\title{
A Unified Theory of Psychological Types
}

\author{
Igor Devetak*
}

September 30, 2020

\begin{abstract}
We review a recently proposed extension of Jung's theory of psychological types and show that it also subsumes the ancient doctrine of the four temperaments, the very first personality classification. We thus arrive at a fundamental theory of types which is both complete and intuitive. The crucial insight, in Jungian terms, is to consider the psychological type of the Self - the totality of the human psyche. Along the way we make significant progress toward unifying Jung's vast opus into a coherent and mathematically structured model of the Self.
\end{abstract}

\section{Contents}

1 Introduction 2

2 Jung's theory of types 3

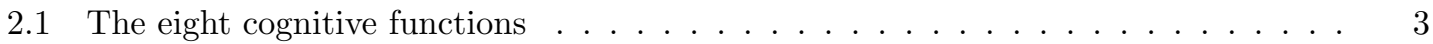

2.2 The psychological type . . . . . . . . . . . . . . . . . . . . 5

3 The structure of the Self: modernizing the collective unconscious 5

3.1 Archetypes of the collective unconscious . . . . . . . . . . . . . . . . . 6

3.2 The masculine-feminine and self-other dualities . . . . . . . . . . . . . . 6

3.3 The higher-lower duality . . . . . . . . . . . . . . . . . . . . . . 7

3.4 The four quadrants of the Self . . . . . . . . . . . . . . . . . . . 8

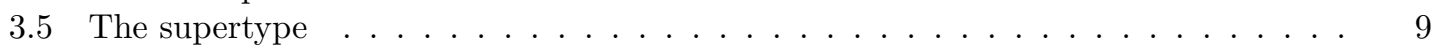

4 The eight elements $\quad 10$

5 The eight archetypes 11

5.1 The atoms of personality . . . . . . . . . . . . . . . . . . . . . 11

5.2 Archetypes and their "cosmic roles" . . . . . . . . . . . . . . . . . . . . . 14

5.3 The complementarity of masculine and feminine archetypes . . . . . . . . . . . . 16

5.4 The negative traits of the archetypes . . . . . . . . . . . . . . . . . . 16

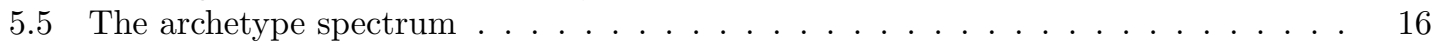

6 Archetypes and the classical temperaments 18

6.1 The four classical elements and four temperaments . . . . . . . . . . . . . . . . . 18

6.2 The four temperaments in relation to the archetype cycle . . . . . . . . . . . . 19

6.3 Threshold dynamics . . . . . . . . . . . . . . . . . . . . . . . . . . . 19

7 The archetype spectrum through examples $\quad 21$

${ }^{*}$ The author is with Systematica Investments, 1201 Geneva, Switzerland. Email address: igordevetak@gmail.com 
A Appendix: Description of the eight elements 24

B Appendix: Metaphors for the archetypes $\quad 25$

B.1 Archetypes in relation to the life cycle . . . . . . . . . . . . . . . . . . . . 25

B.2 Archetypes in relation to the four seasons . . . . . . . . . . . . . . . . . 26

$\begin{array}{ll}\text { C Archetypes across cultures } & 27\end{array}$

\section{Introduction}

C.G. Jung established the first modern theory of psychological types a century ago [1]. While the theory relies on solid theoretical principles with satisfying logical properties, it still does not enjoy universal acceptance. Jung's theory was subsequently interpreted and popularized by MyersBriggs [2]. Critics of the Myers-Briggs Type Indicator (MBTI) and, by extension, Jung's original work deem it too complex with its 16 different types, yet unable to account for all the traits of an individual. Lately data driven empirical models, such as the Big Five factor model (e.g. [3]), have gained in popularity. They are simpler and seem to stand up to statistical verification better than the MBTI. Does this mean that we should give up on a first principles approach? Does the psychological type as a fundamental and unchangeable property of the individual even exist?

Here we argue that, yes, there is such a thing as psychological type, and Jung's work is the right starting point. Recently an extension of Jung's theory has been proposed [4] (inspired by quantum information theory) which incorporates a number of other Jungian concepts such as the countersexual Anima/Animus, the ineffable Senex and the all-encompassing Self $[5,6]$. The main point of this extended theory of types is that the whole Self needs to be considered when speaking of the psychological type: the Self-type or supertype. In particular this means that the countersexual "half" of the psyche (the feminine Anima in a man and the masculine Animus in a woman) has a major effect on the manifested traits of a person. Conversely, personality theory holds the key to a practical understanding of these deep Jungian notions.

In this paper we review the theory of supertypes and elaborate on its practical ramifications. First we map Jung's eight cognitive functions to the more intuitive eight elements. Then we show how appropriate combinations of the elements give rise to the basic atoms of personality: the eight archetypal personalities or archetypes ${ }^{1}$ for short - four masculine and four feminine ones. We equate the eight archetypes with masculine and feminine versions of the four temperaments, the original personality theory of antiquity attributed to Hippocrates and Galen. We also show how the supertype can be meaningfully decomposed into archetypes. Learning to distinguish between the archetypes is the key to determining the supertype of an individual.

An interesting feature of the theory is that every supertype contains all eight archetypes, just like white light contains all the colours of the rainbow. This is how we can account for the similarity between people. The difference between people comes from the hierarchical organization of the archetypes within the Self. If the gender of a given archetype does not match the sex of the individual, or if the archetype is associated with the Anima/Animus, or if it is associated with the Senex, then it may be less pertinent to the traits of the individual.

A disclaimer is in order. This work emphasises the distinction between masculine and feminine archetypes. These terms are carefully chosen, and refer to the masculine and feminine as abstract principles rather than biological sex (male vs. female). The archetypes are strongly charged with gender and equating them to a physical man or woman would inevitably result in a stereotype. In reality the Self is composed of an equal number of masculine and feminine archetypes regardless

\footnotetext{
${ }^{1}$ not to be confused with Jung's use of the the term in his work on the collective unconscious
} 


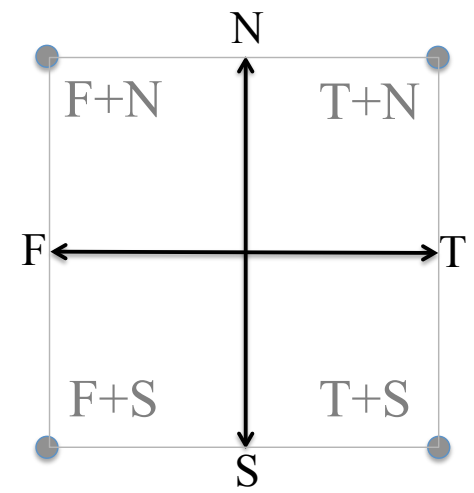

Figure 1: The four elementary cognitive functions as the four cardinal directions

of sex. However, in accord with the solve et coagula adage, to be able to say anything meaningful we first need to distinguish before we unite.

\section{Jung's theory of types}

\subsection{The eight cognitive functions}

Jung defined the four elementary cognitive functions: intuition $(\mathrm{N})$, sensation $(\mathrm{S})$, thinking $(\mathrm{T})$ and feeling (F). They are categorized as irrational vs. rational.

1. The opposing irrational functions, intuition $(\mathrm{N})$ and sensation $(\mathrm{S})$, are neutral and have to do with perception. Sensation takes in the raw information passively, as is, and simply experiences it. Intuition involves a fully active, collaborative approach in which we seek out the information, engage with it, interpret it.

2. The opposing rational functions, thinking $(\mathrm{T})$ and feeling $(\mathrm{F})$, have to do with judgment. They operate in the dual setting of true/false, like/dislike, etc. Thinking is judging based on objective logic and hard facts. Feeling is judging based on "soft" subjective considerations of an aesthetic or emotional nature.

The elementary cognitive functions are often represented as the four cardinal directions (Fig. 1). Thinking and feeling are diametric opposites, as are sensation and intuition. Rational and irrational functions should not be viewed as opposite but complementary. The F-T and S-N axes divide the plane into four parts or quadrants. For instance the first quadrant corresponds to combining thinking and intuition, the second to combining intuition and feeling, etc.

In addition to irrationality ( $\mathrm{N}$ vs. $\mathrm{S}$ ) and rationality (T vs. $\mathrm{F}$ ) there is a third dimension, namely attitude. Jung defined a person to be extroverted (e) if naturally more interested in the outer, physical world and introverted (i) if naturally more interested in the inner world. Correspondingly, each of the four elementary functions comes in two flavours, extroverted and introverted, resulting in a total of eight composite cognitive functions (hereafter referred to simply as the eight cognitive functions): Ne, Ni, Se, Si, Te, Ti, Fe and Fi.

We can represent the eight composite cognitive functions as points in three dimensions (Fig. 2a). In addition to the F-T and S-N axes from Fig. 1 we have a third i-e axis. The cognitive functions lie on the front and rear faces of a cube aligned with these three axes. As in the two dimensional case, the cognitive functions naturally form rational-irrational cognitive function pairs, associated with the eight corners of the cube (Fig. 2b). We will refer to these cognitive function pairs as the eight directed types. 


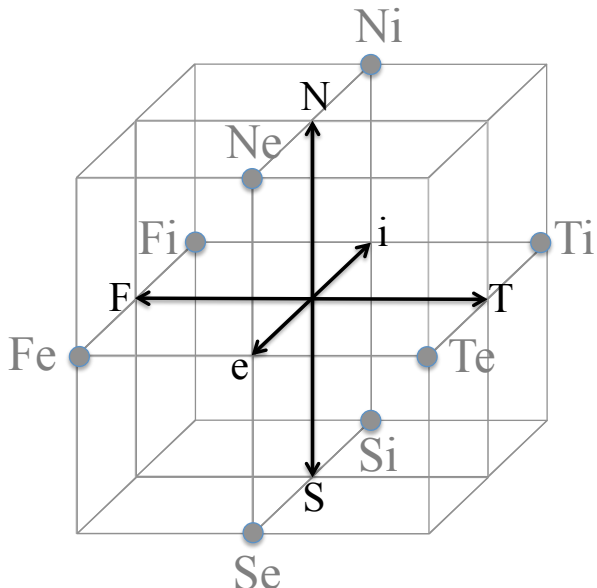

(a)

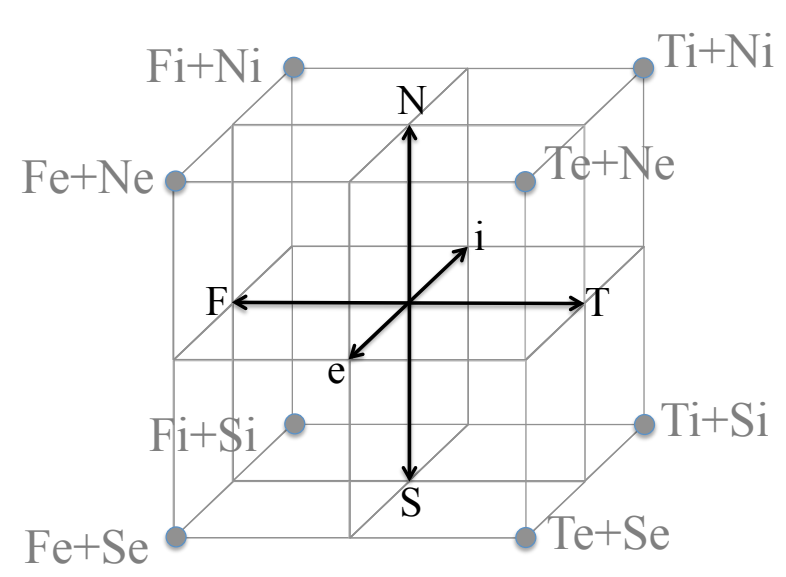

(b)

Figure 2: The eight cognitive functions (a) and the resulting eight directed types (b)

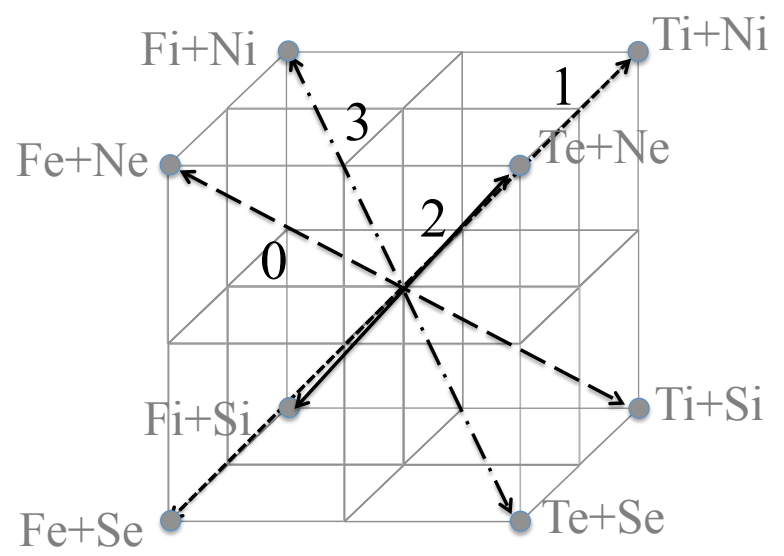

Figure 3: The four undirected types 0,1,2 and 3 correspond to the four diagonals of a cube 


\begin{tabular}{|c|c|c|}
\hline Type & Conscious Directed Type & Unconscious Directed Type \\
\hline $0 \mathrm{i}$ & $\mathrm{Ti}+\mathrm{Si}$ & $\mathrm{Fe}+\mathrm{Ne}$ \\
\hline $0 \mathrm{e}$ & $\mathrm{Fe}+\mathrm{Ne}$ & $\mathrm{Ti}+\mathrm{Si}$ \\
\hline $1 \mathrm{i}$ & $\mathrm{Ti}+\mathrm{Ni}$ & $\mathrm{Fe}+\mathrm{Se}$ \\
\hline $1 \mathrm{e}$ & $\mathrm{Fe}+\mathrm{Se}$ & $\mathrm{Ti}+\mathrm{Ni}$ \\
\hline $2 \mathrm{i}$ & $\mathrm{Fi}+\mathrm{Si}$ & $\mathrm{Te}+\mathrm{Ne}$ \\
\hline $2 \mathrm{e}$ & $\mathrm{Te}+\mathrm{Ne}$ & $\mathrm{Te}+\mathrm{Si}$ \\
\hline $3 \mathrm{i}$ & $\mathrm{Fi}+\mathrm{Ni}$ & $\mathrm{Fi}+\mathrm{Ni}$ \\
\hline $3 \mathrm{e}$ & $\mathrm{Te}+\mathrm{Se}$ & \\
\hline
\end{tabular}

Table 1: The eight distinct psychological (sub)types

\subsection{The psychological type}

Jung's theory of types can be expressed by the following two postulates. For a given individual:

1. The conscious mind has a preferred directed type, one of the eight corners of the cube from Fig. 2b.

2. The unconscious mind also has a preferred directed type: the one antipodal to (as far away as possible from) the conscious one. Thus the unconscious perfectly balances the conscious.

Taking into consideration both the conscious and unconscious preferences, we distinguish between four undirected types which we label by numbers $0,1,2$ and 3 , shown in Fig. 3. Type 0 contains the antipodal $\mathrm{Fe}+\mathrm{Ne}$ and $\mathrm{Ti}+\mathrm{Si}$. Depending on which of the two is the conscious preference we distinguish between subtypes 0e and 0i respectively. Similarly type 1 is composed of $\mathrm{Fe}+\mathrm{Se}$ and $\mathrm{Ti}+\mathrm{Ni}$, type 2 is composed of $\mathrm{Te}+\mathrm{Ne}$ and $\mathrm{Fi}+\mathrm{Si}$, and type 3 is composed of $\mathrm{Te}+\mathrm{Se}$ and $\mathrm{Fi}+\mathrm{Ni}$, each with their introverted and extroverted subtypes. The four types and eight subtypes are summarized in Table 1.

The reader will notice that our interpretation of Jung's theory of types is somewhat different from that of Myers-Briggs ${ }^{2}$. Our nomenclature highlights that it is usually easier to establish whether the undirected type is $0,1,2$ or 3 , than whether a preference is conscious or unconscious. Thus the i/e subtype is a second order consideration. By ignoring the possible rational-irrational skew, and giving the attitude secondary importance, we are down to four types - which is much easier to handle.

\section{The structure of the Self: modernizing the collective un- conscious}

In his later work $[5,6]$ Jung discovered deeper aspects of the psyche that go beyond the consciousunconscious dichotomy. He introduced a number of concepts: the Anima, the Senex and the Self which he broadly designated as "archetypes of the collective unconscious". Jung had a direct experience of these archetypes, mainly through dreams and visions [7]; unfortunately it is not

\footnotetext{
${ }^{2}$ There are two important differences between our classification and MBTI. Firstly, MBTI emphasizes that the mixture of irrational and rational cognitive functions is inevitably skewed toward one of the two. For example when we say that the conscious directed type is $\mathrm{Fi}+\mathrm{Si}$, MBTI would characterize it as dominant $\mathrm{Fi}$ and secondary $\mathrm{Si}$, or vice versa. From our geometrical perspective this distinction is of minor importance and hard to asses, while for MBTI this is the most important feature of the psychological type. Secondly, and much more seriously, MBTI insists that the primary and secondary cognitive functions have opposite attitudes. So MBTI would actually put Fi+Ne in the conscious and $\mathrm{Te}+\mathrm{Si}$ in the unconscious. From the point of view of geometry and mathematical structure this choice does not appear natural.
} 
always clear what their meaning is from a more rational standpoint. In this section we reinterpret them in a structured way.

\subsection{Archetypes of the collective unconscious}

Let us briefly summarize Jung's take on the subject.

- Anima/Animus. In the psyche of male human there is a female counterpart which he called the Anima. Correspondingly there is a male Animus in the psyche of a woman. The Anima represents the archetypal woman most ideally suited to the personality of the subject in the sense of provoking attraction, fascination and a deep sense of connection. It may also manifest as the subject taking on the characteristics of the Anima in his own personality.

- Senex. Unlike the Anima, the Senex is of the same sex as the subject. Jung associated the Senex ("Wise Old Man") with some sort of guardian figure from a higher plane of existence. It remains unclear what the female equivalent of the Senex is.

- Self. The Self is simply the totality of the psyche, and as such subsumes the Anima and the Senex as integral parts. Jung likened the Self to a mandala, or kaleidoscope-like geometrical pattern.

We take the approach of building a model of the Self. The Self is all-encompassing, and its mandala-like structure suggests that it can be subdivided. This subdivision is governed by two dualities:

1. The masculine-feminine duality (equivalently the self-other duality), related to the Anima/Animus.

2. The higher-lower duality, related to the Senex.

\subsection{The masculine-feminine and self-other dualities}

The notion of gender is of immense importance. We all know the difference between a male and female on a concrete biological level. Here we are interested in a characterization of the masculine and feminine principles. We propose the following well known statements, the first of which should be taken as a definition.

- The masculine separates and the feminine unites.

- The masculine is local or microscopic and the feminine is global or macroscopic.

- The masculine is linear and the feminine is circular.

- The masculine gives purpose to the feminine; the feminine gives life to the masculine.

- The masculine is will and the feminine is desire.

The masculine and feminine principles perfectly complement each other. The union of man and woman is an obvious metaphor for this. Anatomically they are designed to fit together and psychologically they have the potential to balance each other out.

There is another important duality: that between yourself and the other. Why can we not live in isolation? Why do we feel lonely without someone else? Painful though it may be, this serves as a reminder of self-other divide. The two dualities, masculine-feminine and self-other, are intimately linked. In order to form a whole, self and other should be complementary in nature, 
like two pieces of a jigsaw puzzle. Going back to our metaphor, when a man and woman are in love they feel like they need nothing else in the world except for each other.

We have set the stage for the first division of the Self into two equal parts: the "self" part of the Self (which we call the core Self) and the "other" part of the Self (which we call the complement Self). In line with the above discussion, the core and complement have opposite gender. A male has a masculine core and a feminine complement, the Anima. A female has a feminine core and a masculine complement, the Animus.

Jung was a pioneer the exploration of the complement, and documented his experience in his famous Red Book [7]. During a period of personal crisis he had regular dreams of and visionary conversations with a mysterious woman he identified with his Anima. These visions were coming from deep inside, but he was able to distinguish them from the core mind thanks to their explicit female form. Around the same time he started a long term extramarital relationship with Toni Wolff, a woman he associated with his Anima. From Jung's experience we can learn that the complement has an internal and an external aspect; in his own way Jung was trying to piece them together.

Regarding the external aspect: if the complement is the "other" it is natural that it is found on the outside. A metaphor for the Self is a fetus living in the mother's womb. The fetus is the core, in the interior, while the placenta is the complement, on the exterior. The placenta is the personal environment of the fetus; it provides it with absolutely everything it needs. Together they form a whole.

Yet, paradoxically, the mind of the complement can be accessed, its voice heard and its feelings felt. This is the internal aspect of the complement. In fact most of us regularly identify with the opposite sex without necessarily being aware of it. In the case of homosexuality this identification is persistent. However it also happens to heterosexuals, for instance in common domestic situations. Jung points out that when a heterosexual couple fights the man temporarily identifies with his Anima and the woman with her Animus. Because people are usually not in touch with their complement, this identification occurs in neurotic outbursts: one becomes "possessed" by the complement. What Jung was able to do was to differentiate the core and the complement on an internal level.

How do we resolve this paradox? A somewhat brute force approach is to declare that the complement is a purely internal concept, a content of the psyche, that gets projected outwards onto a specific person of the opposite sex, the "woman (man) of your life", much like the way an internal complex gets projected on a person we dislike.

We believe the situation is subtler than that. There is a sense in which our external environment is both objective (there are other people with their own Self, essentially independent of us) and subjective (it represents our personal complement, like the placenta of the fetus). Jung alludes to this inseparability of the outer world and inner world in his work on synchronicity [8]. Albeit fascinating, these considerations are beyond the scope of the present work. On a pragmatic level, what concerns us is the personality of the complement. Internally it influences our own personality, while externally it defines what kind of people we may be attracted to on a visceral level.

\subsection{The higher-lower duality}

What do we mean by higher and lower? We propose the following definitions:

- The higher is perfect and the lower is flawed.

- The higher is harmonious and the lower is disordered.

- The higher is sacred and the lower is profane.

- The higher is special and the lower is ordinary. 
- The higher is heavenly and the lower is earthly.

- The higher is infinite, timeless and the lower is limited by space and time.

Despite what it may sound like, the higher-lower duality does not entail some sort of belief system or religious dogma. It is rather that in our psyche there is already a definite idea of perfection. Ask anyone and they will tell you that life is not perfect. This means that somewhere there must also be a notion of its opposite: perfection. Where does this come from? What is our reference point?

We propose that the idea of perfection comes from a memory of perfection. Even though it may feel like we are always in the lower state, we actually experience an alternation between the higher and lower. We could describe this alternation as a continuum of time punctured by moments of eternity. We all experience these moments of eternity in our life, especially as children, but we tend to discard them as unscientific and unreal.

This is the meaning of Jung's Senex. The Senex is associated with some perfect version of ourselves, a perfect state we find ourselves in, not however obtained through laboriously transforming our ordinary self, but as a deus ex machina instant of spontaneous perfection. Every scientist gets a glimpse of this as the solution to a problem comes from nowhere, or an athlete in the moment of "flow". Senex ("Wise Old Man") here refers to glimpses of wisdom, but it could be any other quality associated with perfection such as inspiration, beauty or enchantment. Rather than ignoring these moments of perfection as statistically insignificant, we claim that they actually comprise half of the Self. Much like the the process Jung underwent to differentiate the core from the complement, the work required here is to differentiate the lower from those brief instances of the higher. Even less obviously, in the higher state there is a change in personality, as we shall argue below.

We end this subsection with a few metaphors for the higher-lower duality:

- The juxtaposition of the earth below and the heavens above paints a compelling picture. The image of a translucent morning sky, the lightness of air, the insubstantiality of clouds, the cosmic order of the constellations, the solemn solitude of a star, the harmonious interplay between the sun and the moon: all these provide a stark contrast to our heavy terrestrial predicament. Yet our world comprises both.

- Familiar metaphors for the alternation between the higher an the lower states can be found in the cycle of day and night and the alternation between the waking and dream states.

- Experiencing the higher state brings refreshment and rejuvenation. A metaphor for this is taking a bath. The point is not to be clean and sterile all the time. You live life in the lower, you get dirty, and then you take a bath, you start over. Another example is sleep without dreams. You don't remember anything; you experience a total blackout. It is like a rebirth. You wake up with a fresh body, inspired and beautiful.

\subsection{The four quadrants of the Self}

We return to building our model of the Self. The two dualities we have described, masculinefeminine and higher-lower, divide the Self into four quadrants: the lower masculine, the lower feminine, the higher masculine and the higher feminine. This is represented in Fig. 4. Taking a relative view in which the masculine-feminine duality becomes the self-other duality, we can alternatively label the four quadrants as: the lower core, the lower complement, the higher core and the higher complement. The lower core is what we normally take to be ourselves. The lower complement is what Jung referred to as the Anima/Animus. The higher core is the Senex. The higher complement has not been explicitly mentioned by Jung. It is basically the Senex of the Anima, or equivalently the Anima of the Senex (for a male). 


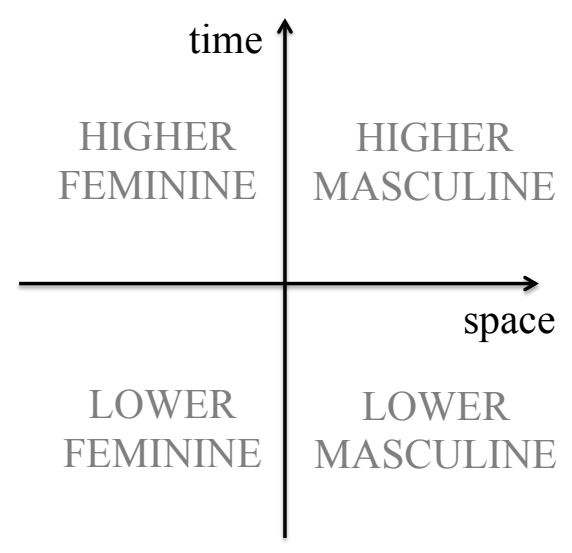

Figure 4: The division of the Self into four quadrants

Note that the relationship between the two dualities is analogous to that between space and time. Experientially the masculine-feminine duality corresponds to the bipartition of psychological space into inner and outer, while in psychological time we experience the alternation of the higher and lower states.

\subsection{The supertype}

We are now ready to present the theory of supertypes, originally proposed in [4]. It can be summarized as follows:

- Each quadrant of the Self is equipped with one of the eight psychological types from Table 1.

- The psychological type as defined by Jung is in fact the one pertaining to the most evident quadrant of the Self: the lower core.

- In line with the conjectured mandala-like structure of the Self, the psychological types of the quadrants are geometrically related. These relationships are defined in Table 2. For the geometrically inclined: the transformations from the lower core to the lower complement, higher core and higher complement are $180^{\circ}$ rotations about the i-e, F-T and N-S axes, respectively.

- The composite structure of the four quadrants together with their respective types is called the supertype, the psychological type of the entire Self. According to the previous point, the supertype is completely determined by the type of the lower core - much like the directed type of the conscious uniquely determines the directed type of the unconscious in Jung's original theory.

What does this mean in practice? For example, if you are a male of the 2e type then your lower complement, your Anima, will be of the 1e type. So not only do you have a psychological type, but there is a completely predictable type of woman that "speaks to you". These sorts of considerations can explain a lot about our love life. Secondly, your higher core is of the 0i type. This means that in those special moments in which you experience perfection you also undergo a personality change. You literally see the world through different eyes. As Jung said, the Senex is yet another level above the Anima in terms of inaccessibility. Thus we will not dwell much more on the higher Self and focus on the way in which the lower core and lower complement fit together. 


\begin{tabular}{|c|c|c|c|}
\hline Lower Core & Lower Complement & Higher Core & Higher Complement \\
\hline $0 \mathrm{i}$ & $3 \mathrm{i}$ & $2 \mathrm{e}$ & $1 \mathrm{e}$ \\
\hline $0 \mathrm{e}$ & $3 \mathrm{e}$ & $2 \mathrm{i}$ & $1 \mathrm{i}$ \\
\hline $1 \mathrm{i}$ & $2 \mathrm{i}$ & $3 \mathrm{e}$ & $0 \mathrm{e}$ \\
\hline $1 \mathrm{e}$ & $2 \mathrm{e}$ & $3 \mathrm{i}$ & $0 \mathrm{i}$ \\
\hline $2 \mathrm{i}$ & $1 \mathrm{i}$ & $0 \mathrm{e}$ & $3 \mathrm{e}$ \\
\hline $2 \mathrm{e}$ & $1 \mathrm{e}$ & $0 \mathrm{i}$ & $3 \mathrm{i}$ \\
\hline $3 \mathrm{i}$ & $0 \mathrm{i}$ & $1 \mathrm{e}$ & $2 \mathrm{e}$ \\
\hline $3 \mathrm{e}$ & $0 \mathrm{e}$ & $1 \mathrm{i}$ & $2 \mathrm{i}$ \\
\hline
\end{tabular}

Table 2: The psychological types of the four quadrants of the Self in relation to the psychological type of the lower core.

We conclude by observing how, as one integrates the deeper levels of the Self, one gains access to additional cognitive functions. This explains how one can have a definite type, yet is able to have some level of understanding of and kinship with those of a different type. Consider again our male of the 2e type:

1. If he only follows his conscious functions and suppresses the unconscious, he has access to two cognitive functions: Te and Ne.

2. As he integrates the unconscious two more cognitive functions are included: Fi and $\mathrm{Si}$, even though he is not able to use them in a focussed, conscious way.

3. By the time the lower complement (conscious and unconscious part) has been integrated, the "missing" type 1 cognitive functions are included: $\mathrm{Fe}$, Se in the conscious and $\mathrm{Ti}$ and $\mathrm{Ni}$ in the unconscious. We have collected all eight, but four of them are unconscious.

4. If one includes the higher core and higher complement we obtain a double covering of the cognitive functions: one from the point of view of the conscious and one from the point of view of the unconscious.

\section{The eight elements}

Having laid out the theory of supertypes, the remainder of this paper is dedicated to the practical issue of recognizing them. Over the decades a big industry of personality tests has been developed to this end. However if the theory is phrased in the most relevant and intuitive way it becomes relatively easy to establish the supertype of a person.

The building blocks of personality are the eight cognitive functions. So they are of paramount importance to our everyday existence. Yet the way they are defined is somewhat dry and academic. We will try to breathe some life into them by "rebranding" them as the eight elements. The eight elements should be defined in a way that makes the following claims possible:

- The eight elements are the basic ingredients out of which the psychological experience of being human is composed. They cannot be broken down into smaller units.

- Together the eight elements constitute the totality of human experience; nothing is missing. A life in which each of the elements has been directly experienced is a fulfilled life.

We propose a definition of the eight elements through their correspondences with the eight cognitive functions: 
1. Extroverted intuition ( $\mathrm{Ne}$ ) is about active perception of the outer world: seeing opportunities in the external world, potential, manoeuvring between obstacles. It is associated with vitality and life energy. The corresponding element is Libido.

2. Introverted intuition $(\mathrm{Ni})$ is about active perception of the inner world: having panoramic vision on an abstract level, flashes of clarity and sudden understanding. The corresponding element is Spirit.

3. Extroverted sensation (Se) is about passive perception of the outer world: tactile, bodily sensations, the texture of a situation. As the diametric opposite of $\mathrm{Ni}$ we associate it with the Matter element.

4. Introverted sensation $(\mathrm{Si})$ is about passive perception of the inner world: form as images, symbols, dreams. The corresponding element is Enchantment.

5. Extroverted thinking $(\mathrm{Te})$ is about objective judgment of the outer world: facts, information, comparisons. The duality is between success and failure. It is associated with goal-oriented action. The corresponding element is the Hero.

6. Introverted thinking $(\mathrm{Ti})$ is about objective judgment of the inner world: the essence of ideas, analogical thought, theory. It is associated with the duality between true and false. The corresponding element is Truth.

7. Extroverted feeling (Fe) is about subjective judgment of the outer world: the duality is between like and dislike. It is associated with beauty. The corresponding element is the Princess.

8. Introverted feeling (Fi) is about subjective judgment of the inner world; it is the basis for emotions. The corresponding element is Love.

The elements carry a sense of energy that is not necessarily conveyed by the cognitive function formulation. You could say that the cognitive functions are the elements viewed through the more narrow prism of introverted thinking.

Table 3 shows the eight elements and their properties: a single letter abbreviation (such as L for Love), the corresponding cognitive function as defined above, and whether said cognitive function lies in the rational or irrational plane. Next, we claim that the two dualities described in Section 3 are also reflected in the elements. In accord with the the masculine-feminine duality there is a gender attached to each element (e.g. feminine for the Princess). In accord with the the higher-lower duality there is a state attached to each element (e.g. higher for Spirit). Lastly, we can also associate an intuitive colour to each element (such as black for Matter). We provide more detail in Appendix A and give an informal account of the eight elements.

\section{The eight archetypes}

\subsection{The atoms of personality}

To understand the aggregate personality of the Self it is extremely helpful to decompose it into sub-personalities. We propose the following postulates:

- There is such a thing as a personality "atom", the smallest unit of personality. We will call them archetypal personalities or archetypes ${ }^{3}$ for short.

\footnotetext{
${ }^{3}$ Now that we have embedded Jung's archetypes of the collective unconscious into our model of the Self, the term "archetype" has been freed up to have a strict personality connotation, at least in the context of this work.
} 


\begin{tabular}{|c|c|c|c|c|c|}
\hline Element & Cognitive function & Plane & Gender & State & Color \\
\hline Spirit (S) & $\mathrm{Ni}$ & irrational & masculine & higher & white \\
\hline Libido (B) & $\mathrm{Ne}$ & irrational & masculine & lower & cyan \\
\hline Enchantment (E) & $\mathrm{Si}$ & irrational & feminine & higher & magenta \\
\hline Matter (M) & $\mathrm{Se}$ & irrational & feminine & lower & black \\
\hline Truth (T) & $\mathrm{Ti}$ & rational & masculine & higher & blue \\
\hline Hero (H) & $\mathrm{Te}$ & rational & masculine & lower & navy blue \\
\hline Love (L) & $\mathrm{Fi}$ & rational & feminine & lower & red \\
\hline Princess (P) & $\mathrm{Fe}$ & rational & feminine & higher & pink \\
\hline
\end{tabular}

Table 3: The eight elements and their properties

\begin{tabular}{|c|c|c|c|}
\hline Archetype name & Gender & Rational element & Irrational element \\
\hline God $(G)$ & masculine & Truth & Spirit \\
\hline Hero $(H)$ & masculine & Hero & Libido \\
\hline Woman $(W)$ & feminine & Love & Matter \\
\hline Princess $(P)$ & feminine & Princess & Enchantment \\
\hline Heavenly Hero $(h H)$ & masculine & Hero & Spirit \\
\hline Earthly God $(e G)$ & masculine & Truth & Libido \\
\hline Heavenly Woman $(h H)$ & feminine & Love & Enchantment \\
\hline Earthly Princess $(e P)$ & feminine & Princess & Matter \\
\hline
\end{tabular}

Table 4: The composition of the eight archetypes

- An archetype has a definite gender. It is composed of one rational and one irrational element of said gender.

Consulting Table 3, it follows that the masculine archetypes are a combination of one of the rational Truth or Hero elements with one of the irrational Spirit or Libido elements; and the feminine archetypes are a combination of one of the rational Princess or Love elements with one of the irrational Enchantment or Matter elements. The eight resulting archetypes (four feminine and four masculine) are worked out in Table 4. The single/double letter abbreviations for the archetypes are in italics.

We proceed to justify our choice of the archetype names, and expand on their meaning. A natural way to visually organize the eight archetypes is shown in Fig. 5. There is a clockwise masculine cycle and a counterclockwise feminine cycle. Each cycle has four characteristic positions, corresponding to the four cardinal directions: top, bottom, left and right. Each position is associated with an archetype. The upper half of the picture is associated with the higher and the lower half with the lower state.

Consider the masculine cycle. On the top of the trajectory we have the God archetype, comprising Truth and Spirit. These are the two higher masculine elements and they combine into the ideal higher masculine archetype. If we bring to mind of the "personality" of the Creator God of the Old Testament we find the expansive inspiration of Spirit and the structure and order of Truth.

Correspondingly at the bottom of the trajectory we have the Hero archetype (not to be confused with the Hero element), comprising the lower masculine Hero and Libido elements. The Hero archetype is ideally suited for a fulfilled male existence in the lower. In mythology the Hero is not only goal oriented (to win a battle or rescue a princess), which is the essence of the Hero element, but must also have cunningness and agility, aspects of the Libido element, in order to compensate for the enemy possessing greater physical strength or some kind of higher knowledge. 


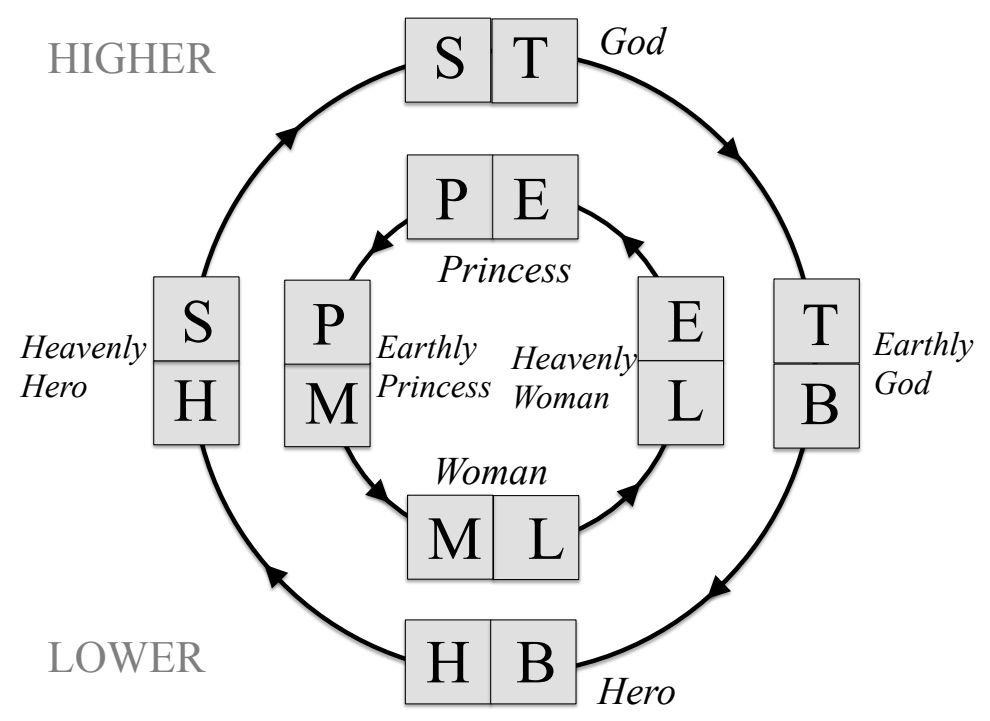

Figure 5: The eight archetypes arranged in a double circular diagram

Greek mythology particularly accentuates the polarity between gods and heroes.

Before carrying on with the remaining two masculine archetypes, let us turn our attention to the feminine cycle. On the bottom of the trajectory we have the Woman archetype, comprising Love and Matter. These are the two lower feminine elements and they combine into the ideal lower feminine archetype. This is the female equivalent of the masculine God - the Woman rules over the lower like God rules over the higher. If God is related to patriarchy and monotheism, the Woman is related matriarchy and Earth Goddess/Nature worship. It is deliberate that we call this archetype Woman and not Goddess, because the lower is associated with the ordinary. Yet this ordinary is sacred: the sacred qualities of nature, womanhood and motherhood. Love and Matter complement each other very well. Without Love, the heaviness of Matter would be unbearable. Love is the light of the lower state. Love gives life to Matter. The combination gives rise to the various nuances of Woman: sensual, carnal, material, maternal, nurturing, comforting.

Correspondingly at the top of the trajectory we have the Princess archetype (not to be confused with the Princess element), comprising the higher feminine Princess and Enchantment elements. Aspects of this heavenly, youthful, virginal archetype are found not only in the Christian Virgin Mary but are authentically present in the psyche of little girls. A testimony to the power of the Princess archetype is the success of Disney movies. Also the Cinderella story is a perfect example of what it is like when a Princess is faced with the grim conditions of material existence. What is a natural habitat of a Woman is regarded as something to escape from, or better still be saved from, from the point of view of the Princess.

The four archetypes defined so far, God, Hero, Woman and Princess, lie squarely in the higher or the lower. We call these archetypes stable. We can relate the above discussion to a passage from Jung's esoteric text "Seven Sermons to the Dead", published as part of the Red Book [7].

The world of the gods is made manifest in spirituality and in sexuality.

The sexuality of man is more of the earth, the sexuality of woman is more of the spirit.

The spirituality of man is more of heaven, it goes to the greater.

The spirituality of woman is more of the earth, it goes to the smaller. 
This quote contains a lot of information. Firstly there is a clear emphasis on the fundamental nature of the masculine-feminine and higher-lower ("heaven-earth") dualities. There is also a third duality, spirituality vs. sexuality, logically related to the first two. In our language: the irrational elements, Jung's "world of gods" 4 , can be subdivided according to this third duality. Spirituality refers to something that belongs to oneself and is represented by the Spirit and Matter elements (one's mind and body, respectively); while sexuality is relational and is represented by the Enchantment and Libido elements (mesmerising attraction and sexual energy, respectively). The quote confirms that Libido is lower masculine, Enchantment is higher feminine, Spirit is higher masculine and Matter is lower feminine. Mixed with the appropriate rational elements ${ }^{5}$, we obtain the four stable archetypes.

Returning to Fig. 5, there are four archetypes left to consider that live on the transition between the higher and lower. We call them dynamic as they are either ascending or descending. While the stable archetypes have a clearly defined identity, the dynamic archetypes are to a certain extent oriented toward their stable complementary archetype ${ }^{6}$. The four complementary archetype pairs are God and Heavenly Woman, Princess and Heavenly Hero, Hero and Earthly Princes, and Woman and Earthly God. Fig. 5 shows them separated by $90^{\circ}$ and moving towards each other.

In the masculine cycle we have the ascending Heavenly Hero archetype, composed of the Hero and Spirit elements. He has a goal, but he is fuelled by Sprit so his goal is an impossible, heavenly goal, which gives him a somewhat crazy, impressive brilliance. Quite the opposite is the descending Earthly God archetype, composed of the Truth and Libido elements. The Earthly God is coming from the higher and is interested in taking advantage of his superior perspective. He has the calmness and ability to think his plan through, but will, when the time is right, swiftly bring it to conclusion with the help of Libido. While the Heavenly Hero does everything to impress and be visible, the Earthly God acts in secret and makes use of his invisibility. The Heavenly Hero is intent on sweeping the Princess off her feet. The Earthly God is interested in harvesting what the Woman has to offer, albeit in a protective and attentive way.

In the feminine cycle we have the ascending Heavenly Woman archetype, composed of the Love and Enchantment elements. The Heavenly Woman has a fiery, seductive quality: she is set on seducing God himself, no ordinary Hero will suffice. On the descending side we have the Earthly Princess composed of the Princess and Matter elements. Opposite from the flamboyant Heavenly Woman, she comes across as disinterested, unapproachable, even self sufficient. Armed with beauty she knows she doesn't need to make much of an effort. Armed with Matter, she knows when to seal the deal. This kind of challenge is exactly what the Hero needs.

\subsection{Archetypes and their "cosmic roles"}

The masculine separates. Separation is linked to activity and will. ${ }^{7}$ The masculine archetypes thus specialize in a particular domain of activity:

\footnotetext{
${ }^{4}$ Earlier in the text Jung effectively equates the "four gods" with the irrational elements, Spirit, Enchantment, Libido and Matter:

Four is the number of the principal gods, as four is the number of the world's measurements.

One is the beginning, the god-sun.

Two is Eros; for he binds twain together and outspreads himself in brightness.

Three is the Tree of Life, for it fills space with bodily forms.

Four is the devil, for he opens all that is closed. All that is formed of bodily nature doth he dissolve; he is the destroyer in whom everything is brought to nothing.

${ }^{5}$ Later in the text Jung introduces the four "supernatural demons": the Celestial Mother, the Phallos, the White Bird and the Serpent which can be identified with the Princess, Hero, Truth and Love elements respectively.

${ }^{6}$ The relation between complementary archetypes and the core-complement duality will be established in Section 5.5 .

${ }^{7}$ According to the second law of thermodynamics, entropy (disorder, mixing) increases spontaneously; to undo this, directed energy or work is required.
} 
1. The God archetype is composed of the Truth and Spirit elements. The combination of the two is divine creativity. His mission is creation as an end in itself.

2. The Hero archetype is composed of the Hero and Libido elements. His game is to set himself goals and then accomplish them. It is the accomplishment that brings satisfaction. The directed focus of the Hero element and the nimbleness of Libido is a wining combination.

3. The Heavenly Hero archetype is composed of the Hero and Spirit elements. His goals are too grand, too cosmic to even be thought of as goals in the ordinary sense. What would seem like a huge success to anyone else, the Heavenly Hero sees as just another intermediate step towards heaven. The only thing that can satisfy him is the feeling of freedom itself, the freedom to do whatever he wants, the freedom to keep trying.

4. The Earthly God archetype is composed of the Truth and Libido elements. Unlike the God archetype, he is interested in applied truth, benefitting from his knowledge, intellect and intuition. Lacking the drive of the Hero, he needs to outsmart him, and this is what brings satisfaction.

The feminine joins. Joining does not come about as a result of action. It occurs spontaneously as a result of a particular way of being. ${ }^{8}$ Joining happens through the four feminine elements: Love, Enchantment, Princess and Matter. It always requires feedback or reflection from the masculine to the feminine. This feedback is a confirmation that the joining was successful. The masculine thus serves as a mirror for the feminine.

1. The introverted elements require a communion, a meeting of hearts as it were. Joining through Love requires a constant and free-flowing exchange of love. Joining through Enchantment requires the masculine and feminine to enter the infinite field of enchantment together.

2. The extroverted elements require a complementary response. Joining through Matter requires the feminine to be proud of her embodiment, to feel like matter, and the masculine to desire her as such. Joining through the Princess element requires an admiration on the part of the masculine and the need to be appreciated for her beauty on the part of the feminine.

Each archetype combines two elements, thus producing a unique flavour of joining:

1. The Princess archetype is composed of the Princess and Enchantment elements. The combination of sharing the field of enchantment and appreciation of her beauty means that she needs to be put on a pedestal, to be venerated.

2. The Woman archetype is composed of the Love and Matter elements. She needs to feel protected, cared for and cherished, which corresponds to being desired as matter but with a continuous exchange of love.

3. The Earthly Princess is composed of the Princess and Matter elements. She wants to be desired as matter, but beautiful matter that one has to conquer, like a treasure or a fortress.

4. The Heavenly Woman is composed of the Love and Enchantment elements. She needs to generate a field of enchantment and love around her, so that men are constantly fascinated by her, infatuated with her, desperately in love with her.

\footnotetext{
${ }^{8}$ See footnote 7 .
} 


\subsection{The complementarity of masculine and feminine archetypes}

Recall the concept of complementary archetypes. We shall argue that the mission of the masculine archetype is a perfect match for the style of joining of the complementary female archetype. In other words, a female archetype is naturally reflected by the complementary masculine archetype.

- The Heavenly Hero aims for the stars and there he finds the Princess, his complementary archetype. She represents for him that unachievable ideal, that object of veneration.

- The Earthly God is smart. Why bust your back hunting if you can carve out your own territory, cultivate it and reap the benefits. He will naturally cherish and protect his complement, the Woman archetype. The pimp-prostitute rapport is a particularly compelling, albeit degenerate, example.

- The Hero likes a challenge and will naturally try to conquer his complementary archetype, the Earthly Princess. While being somewhat aloof and "hard to get", if he persists she will actually end up giving him the satisfaction of conquest.

- The God already leads an intangible existence. For him the open-ended sharing in the field of love and enchantment generated by the Heavenly Woman comes naturally. She is his inspiration, his muse.

\subsection{The negative traits of the archetypes}

There are certain predictable traits of the different archetypes, associated with their position in the cycle. From the point of view of other archetypes these traits could be considered negative.

- The higher archetypes (God and Princess) may be perceived as "self-absorbed". The higher is a very exclusive place.

- The lower archetypes (Hero and Woman) may be perceived as "domineering". The lower is their kingdom.

- The ascending archetypes (Heavenly Hero and Heavenly Woman) may be perceived as "provokers". Part of their job is to provoke their complement out of self-absorption.

- The descending archetypes (Earthly God and Earthly Princess) may be perceived as "exploiters". Coming from above they ask themselves how to make the best use of their complement that rules the lower so tirelessly.

On a fundamental level these traits are not negative at all, as long as they are not loaded with complexes. They are natural and necessary for the world to go around, so to speak.

We continue our discussion of archetypes in the Appendix. In Appendix B we present two metaphors for the archetypes: the stages of life and the four seasons. In Appendix $\mathrm{C}$ we comment on how different archetypes dominate different cultures across the globe.

\subsection{The archetype spectrum}

It is time to see how the eight archetypes fit into the theory of supertypes. As already discussed, the complement plays a dual role in the manifested personality, by influencing the personality of the core and/or defining the personality of the opposite sex that attracts it. In what follows we set aside the relatively inaccessible higher quadrants and focus on the combined effect of the lower core and lower complement.

Table 5 is obtained by combining Tables 1 and 2, together with the correspondences between elements and cognitive functions from Table 3. It shows the elements available in the lower core 


\begin{tabular}{|c|c|c|}
\hline Lower Core Type & Lower Core Elements & Lower Complement Elements \\
\hline 0 & $\mathrm{~T}+\mathrm{B}+\mathrm{P}+\mathrm{E}$ & $\mathrm{H}+\mathrm{S}+\mathrm{L}+\mathrm{M}$ \\
\hline 1 & $\mathrm{~T}+\mathrm{S}+\mathrm{P}+\mathrm{M}$ & $\mathrm{H}+\mathrm{B}+\mathrm{L}+\mathrm{E}$ \\
\hline 2 & $\mathrm{H}+\mathrm{B}+\mathrm{L}+\mathrm{E}$ & $\mathrm{T}+\mathrm{S}+\mathrm{P}+\mathrm{M}$ \\
\hline 3 & $\mathrm{H}+\mathrm{S}+\mathrm{L}+\mathrm{M}$ & $\mathrm{T}+\mathrm{B}+\mathrm{P}+\mathrm{E}$ \\
\hline
\end{tabular}

Table 5: The elements of the lower core and lower complement versus type

and lower complement for each of the four undirected types (the attitude/ subtype plays no role here). They are complementary in that together they cover all eight elements, regardless of type. So how are we supposed to tell the different types apart?

The trick is to break up the aggregate personality into archetypes. We take the example of a type 1 male. In what follows we shall prefix the type by $\mathrm{M}$ or $\mathrm{F}$ to specify masculine or feminine gender, respectively.

- M1 is the type of his lower core, which is masculine. From Table 5 we read off the elements present in this type: Truth, Spirit, Princess and Matter. The first two of these combine into the masculine God archetype and the second two into the feminine Earthly Princess archetype. By default the God archetype is going to dominate his personality because his gender matches that of the lower core. We call this the primary archetype. The Earthly Princess is the secondary archetype. Even though she is composed of feminine elements, they are set against the masculine lower core background that "neutralizes" her femininity. We call this variation the neutralized Earthly Princess (labeled $e P^{\prime}$ ). Secondary archetypes are by definition neutralized.

- F2 is the type of his lower complement, which is feminine. The elements present in this type are: Love, Enchantment, Hero and Libido. The first two of these combine into the feminine Heavenly Woman archetype and the second two into the masculine Hero archetype. The Hero archetype is actually a neutralized Hero $\left(H^{\prime}\right)$ because he is set against the feminine lower complement background. The neutralized Hero archetype is the tertiary archetype and the fully feminine Heavenly Woman archetype is the quaternary archetype from the point of view of our male subject.

God and Heavenly Woman were defined as complementary archetypes in Section 5.1. We now have a justification for this terminology. The complement of an M1 type is an F2 type. The primary archetype of the former is God while the primary archetype of the latter is Heavenly Woman. This is generally true. The primary archetypes of the lower core and lower complement entities are complementary. So are their secondary, tertiary and quaternary archetypes.

The primary, secondary, tertiary and quaternary archetypes together form the archetype spectrum. The archetype spectrum is worked out for all eight psychological types in Table 6, based on Table 5 and the definitions of the archetypes from Table 4. Note that for each supertype the archetype spectrum traverses the archetype cycle while alternating in gender. For example, the spectrum of F3 is feminine lower $\rightarrow$ masculine ascending $\rightarrow$ feminine higher $\rightarrow$ masculine descending. If the primary archetype is dynamic as opposed to stable then the archetype cycle is traversed in reverse. For example, the spectrum of F2 is feminine ascending $\rightarrow$ masculine lower $\rightarrow$ feminine descending $\rightarrow$ masculine higher.

We will give explicit examples of the archetype spectrum in Section 7. 


\begin{tabular}{|c|c|c|c|c|}
\hline Type & Primary archetype & Secondary archetype & Tertiary archetype & Quaternary archetype \\
\hline M0 & $e G$ & $P^{\prime}$ & $h H^{\prime}$ & $W$ \\
\hline F0 & $P$ & $e G^{\prime}$ & $W^{\prime}$ & $h H$ \\
\hline M1 & $G$ & $e P^{\prime}$ & $H^{\prime}$ & $h W$ \\
\hline F1 & $e P$ & $G^{\prime}$ & $h W^{\prime}$ & $H$ \\
\hline M2 & $H$ & $h W^{\prime}$ & $G^{\prime}$ & $e P$ \\
\hline F2 & $h W$ & $H^{\prime}$ & $e P^{\prime}$ & $G$ \\
\hline M3 & $h H$ & $W^{\prime}$ & $e G^{\prime}$ & $P$ \\
\hline F3 & $W$ & $h H^{\prime}$ & $P^{\prime}$ & $e G$ \\
\hline
\end{tabular}

Table 6: The archetype spectrum of male and female types

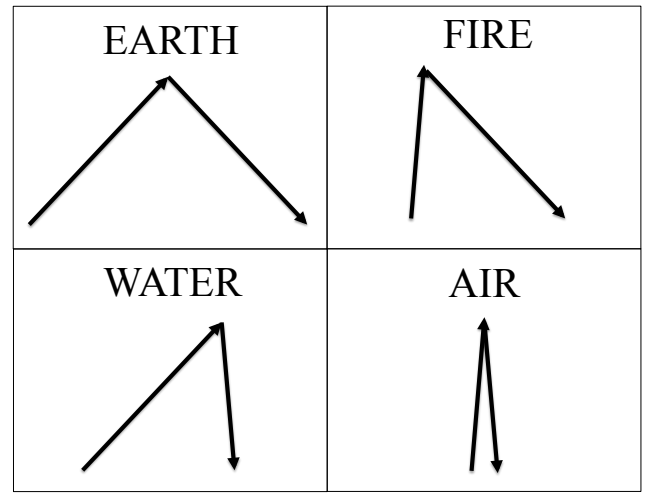

Figure 6: The four classical elements from the response-sustain point of view

\section{Archetypes and the classical temperaments}

\subsection{The four classical elements and four temperaments}

Antiquity viewed both the natural world and human character in terms of the four classical elements: Earth, Water, Fire and Air. The classical elements are combinations of two classical attribute pairs: cold/hot and dry/wet. Earth is cold and dry, Water is cold and wet, Fire is hot and dry, and Air is hot and wet. These attributes have an interpretation in terms of response and sustain. Hot means a fast response to a stimulus, fast excitation; cold means slow excitation. Wet means a short-lived sustain of a stimulus, fast deexcitation; dry means slow deexcitation. Fig. 6 illustrates this. For each element there is a diagram consisting of an excitation and deexcitation phase. The steepness of the directed lines indicates speed. For example, the Fire diagram has a steep ascent (fast excitation, hot) and gradual descent (slow deexcitation, dry).

Human character was mapped to the four classical elements. The four temperaments: melancholic, phlegmatic, choleric and sanguine correspond respectively to Earth, Water, Fire and Air.

1. The melancholic is like Earth: takes a long time to heat up and a long time to cool off afterwards.

2. The phlegmatic is like Water: takes a long time to boil but quickly condensates.

3. The choleric is like Fire: ignites quickly yet takes a long time to be put out.

4. The sanguine is like Air: heats up and cools off quickly. 


\begin{tabular}{|c|c|c|c|c|c|}
\hline Cl. element & Cl. attributes & Response-sustain & Temperament & Position & Archetype (M, F) \\
\hline Earth & cold \& dry & slow-slow & melancholic & higher & $G, P$ \\
\hline Water & cold \& wet & slow-fast & phlegmatic & descending & $e G, e P$ \\
\hline Fire & hot \& dry & fast-slow & choleric & ascending & $h H, h W$ \\
\hline Air & hot \& wet & fast-fast & sanguine & lower & $H, W$ \\
\hline
\end{tabular}

Table 7: The four classical elements and their relation to the eight archetypes

In terms of an emotion such as anger, the choleric would react immediately and hold a grudge for a long time. His opposite, the phlegmatic, would build up anger slowly, silently, before exploding, yet would easily get over it.

\subsection{The four temperaments in relation to the archetype cycle}

We are ready to make the connection between the four temperaments and the theory of supertypes, one of the main results of this work. We saw in Table 6 how each supertype can be decomposed into four of the eight archetypes, traversing the archetype cycle and alternating in gender. Now we will argue that the four temperaments are in exact correspondence with the four positions of the archetype cycle:

1. The melancholic corresponds to the higher position, God in the masculine and Princess in the feminine cycle. Higher archetypes appear melancholic because they are exiled from their natural environment. For them fulfilment in the usual sense is harder to obtain and they tend to retract from the world more than others. It is not easy to maintain the higher in the lower.

2. The sanguine corresponds to the lower position, Hero in the masculine and Woman in the feminine cycle. Lower archetypes are sanguine, lively, pleasure seeking. Fulfilment is found in the world as it is, with all its imperfections; they love life.

3. The phlegmatic corresponds to the descending position, Earthly God in the masculine and Earthly Princess in the feminine cycle. The descending archetypes have already been there, in that special place called the higher. They have a plan, a birds-eye view of the lower, and their idea is to bring the higher down to the lower. They are phlegmatic and laid back because their task is relatively easy. They do not have to work hard like the lower archetypes; they can actually take advantage of the work of others.

4. The choleric corresponds to the ascending position, Heavenly Hero in the masculine and Heavenly Woman in the feminine cycle. Ascending archetypes are choleric, because they cannot find satisfaction in realistic goals and a simple life. They want to personally rise above the lower. The key word here is "aspiration". They aspire to something bigger, more magical, more extraordinary. They refuse to settle for the ordinary, even if life requires them to compromise. They feel that they are special compared to others, and it is important for them to be recognized and visible.

Table 7 summarizes the correspondence between the classical elements, the classical temperaments and the eight archetypes.

\subsection{Threshold dynamics}

Not only is there a correspondence between classical elements/ temperaments and the eight archetypes, but there is an even deeper one between the classical attributes and the eight elements (and hence cognitive functions). Excitation is governed by the rational elements; of these 


\begin{tabular}{|c|c|c|c|}
\hline Classical attribute & Meaning & Element characteristics & Element (M, F) \\
\hline cold & slow excitation & rational \& higher & Truth, Princess \\
\hline hot & fast excitation & rational \& lower & Hero, Love \\
\hline dry & slow deexcitation & irrational \& higher & Spirit, Enchantment \\
\hline wet & fast deexcitation & irrational \& lower & Libido, Matter \\
\hline
\end{tabular}

Table 8: The four classical attributes and their relation to eight elements

\begin{tabular}{|c|c|c|c|}
\hline Element & Gender & Stimulus & Speed \\
\hline Hero & masculine & excitation & fast \\
\hline Truth & masculine & excitation & slow \\
\hline Libido & masculine & deexcitation & fast \\
\hline Spirit & masculine & deexcitation & slow \\
\hline Love & feminine & excitation & fast \\
\hline Princess & feminine & excitation & slow \\
\hline Matter & feminine & deexcitation & fast \\
\hline Enchantment & feminine & deexcitation & slow \\
\hline
\end{tabular}

Table 9: A characterization of the elements in terms of gender, stimulus and speed

the lower ones (Hero and Love) are hot (fast excitation) and the higher ones (Truth and Princess) are cold (slow excitation). Deexcitation is governed by the irrational elements: wet (fast deexcitation) are the lower elements Libido and Matter; dry (slow deexcitation) are the higher elements Spirit and Enchantment. These statements can be reduced to the following postulates:

1. The lower is fast and the higher is slow.

2. Excitation is rational and deexcitation is irrational.

We recapitulate these results in Table 8 . The correspondence between the archetypes and the four temperaments (Table 7) can now be deduced from our postulates. For instance, the phlegmatic is cold + wet, which is Truth + Libido $=$ Earthly God in the masculine and Princess + Matter $=$ Earthly Princess in the feminine.

We now have a characterization of the elements in terms of stimulus: excitation (stimulus on) or deexcitation (stimulus off). The eight different combinations of gender, stimulus and speed uniquely specify the eight elements, so we can rearrange Table 8 as Table 9 .

We can interpret excitation and deexcitation in terms of crossing a threshold. Excitation leads up to the threshold and deexcitation follows it. The four positions of the cycle are thresholds (Fig. 7). The environment on either side of the threshold determines the speed of the excitation/deexcitation: the higher is slow and the lower is fast.

1. Crossing the threshold of the descending archetype one moves from a slow to a fast environment. Thus the excitation is slow and the deexcitation is fast, corresponding to a phlegmatic temperament.

2. Crossing the threshold of the lower archetype one moves from a fast to a fast environment. Thus both excitation and deexcitation are fast, corresponding to a sanguine temperament.

3. Crossing the threshold of the ascending archetype one moves from a fast to a slow environment. Thus the excitation is fast and the deexcitation is slow, corresponding to a choleric temperament. 


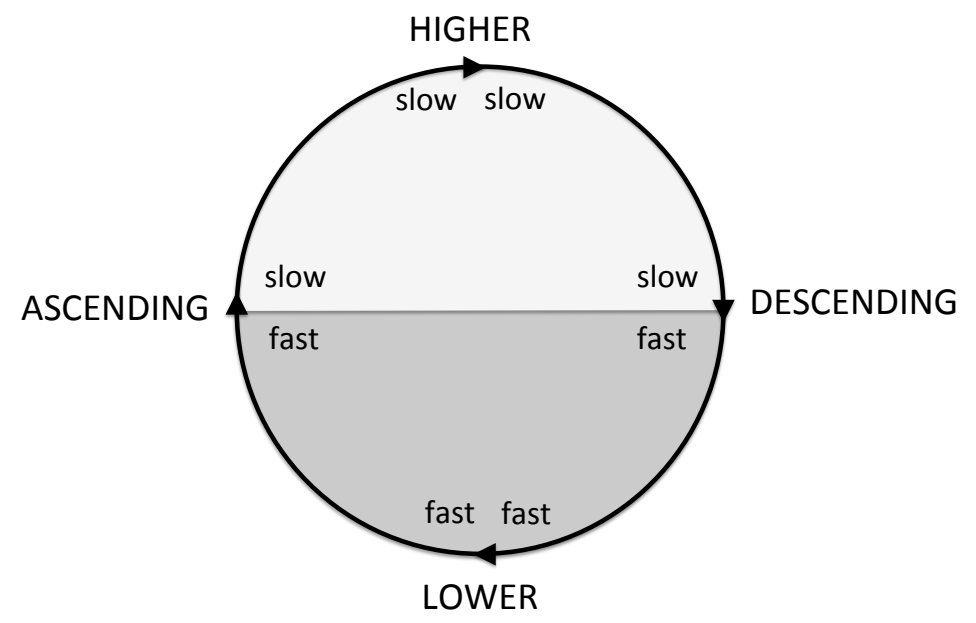

Figure 7: The temperaments arise from crossing the thresholds, the four positions of the cycle

4. Crossing the threshold of the higher archetype one moves from a slow to a slow environment. Thus both excitation and deexcitation are slow, corresponding to a melancholic temperament.

This threshold dynamics can be seen in various examples. The Earthly God is a descending archetype; he is a strategist. He uses the higher element of Truth to slowly plan his action and Libido to swiftly conclude when the time is right. The Hero is a lower archetype. He uses the fast Hero element to quickly respond to a situation and Libido to execute quickly. The Heavenly Woman is an ascending archetype; she joins by way of seduction. The fast Love element quickly draws you in, and the Enchantment keeps you spellbound forever.

\section{The archetype spectrum through examples}

We will illustrate the concept of the archetype spectrum by considering examples of male and female public figures from each of the four types. We will refer to them by their primary archetype.

God. The archetype spectrum of the M1 type is $G-e P^{\prime}-H^{\prime}-h W$. The primary God archetype dominates introverts such as Nikola Tesla or Jiddu Krishnamurthi. Extroverts such as Arnold Schwarzenegger or Rudolf Nureyev manifest a physically solid and shiny secondary neutralized Earthly Princess. The vivacious tertiary neutralized Hero is particularly evident in Freddie Mercury's stage persona, while his off-stage mannerisms are largely influenced by the quaternary Heavenly Woman. Jim Morrison is particularly interesting as he manifests both primary and secondary archetypes, as well as elements of the quaternary one.

Hero. The archetype spectrum of the M2 type is $H-h W^{\prime}-G^{\prime}-e P$. An extroverted M2 is usually dominated by the primary Hero archetype, for instance Michael Jordan or Bruce Springsteen. It is often accompanied by a secondary neutralized Heavenly Woman which ranges from the "sweet" feeling of Sylvester Stallone to the more seductive flavour of Mick Jagger. The smooth and refined quaternary Earthly Princess comes out in Alain Delon. The "good guy", upright image of Ed Sheeran is influenced by the tertiary God archetype. 
Heavenly Hero. The archetype spectrum of the M3 type is $h H-W^{\prime}-e G^{\prime}-P$. The larger-than-life primary Heavenly Hero archetype is exemplified by Elvis, Michael Jackson, John Lennon, Kanye West. Robin Williams additionally incarnates the deeply caring secondary neutralized Woman, while David Bowie and Prince also manifest the quaternary Princess. In Tom Cruise one can also detect the tertiary neutralized Earthly God archetype, which balances the primary archetype with a strategic and calculated focus.

Earthly God. The archetype spectrum of the M0 type is $e G-P^{\prime}-h H^{\prime}-W$. A typical primary Earthly God is found in Robert de Niro and Jack Nicholson. The secondary neutralized Princess is manifested in the likes of Brad Pitt or Johnny Depp. Salvador Dali and Eminem also display the choleric tertiary Heavenly Hero. The quaternary Woman comes out in the more sanguine stage performances of Elton John.

Woman. The archetype spectrum of the F3 type is $W-h H^{\prime}-P^{\prime}-e G$. The primary Woman archetype comes out clearly in Naomi Campbell and Cher. Amy Winehouse and Sharon Stone also exhibit the sharp secondary Heavenly Hero. Whitney Houston largely identified with the chaste tertiary Princess, while Oprah Winfrey has elements of the quaternary Earthly God.

Princess. The archetype spectrum of the F0 type is $P-e G^{\prime}-W^{\prime}-h H$. Classic Princess representatives are Paris Hilton and Farrah Fawcett. Angela Merkel has a strong secondary neutralized Earthly God. The compassionate and nurturing side of Mia Farrow comes from the tertiary Woman archetype. Celine Dion and Ellen DeGeneres display aspects of the quaternary Heavenly Hero archetype.

Earthly Princess. The archetype spectrum of the F1 type is $e P-G^{\prime}-h W^{\prime}-H$. The primary Earthly Princess archetype is found in Kate Middleton and Martha Stewart. Margaret Thatcher's stern aspect comes from the secondary neutralized God. The more emotional performances of Julianne Moore draw on the tertiary neutralized Heavenly Woman. The quaternary Hero comes out in Katharine Hepburn.

Heavenly Woman. The archetype spectrum of the $\mathrm{F} 2$ type is $h W-H^{\prime}-e P^{\prime}-G$. Classic representatives of the primary Heavenly Woman are Marilyn Monroe and Brigitte Bardot. The secondary neutralized Hero commonly manifests in this type, for instance Madonna or Lady Gaga. Catherine Deneuve has assimilated much of her tertiary archetype, the sophisticated neutralized Earthy Princess. Elements of the spiritual quaternary God archetype can be identified in Natalie Portman.

\section{Discussion}

This work makes several contributions. Firstly, it unifies the two most credible personality theories: the most rigorous (Jung's psychological types) and the most ancient (the four temperaments of Galen). We saw how the atoms of Jung's theory, the eight cognitive functions, reinterpreted as our eight elements, combine pairwise into the masculine and feminine versions of the four temperaments, reinterpreted as our eight archetypes. We then showed how the supertype, i.e. the Jungian type of the Self, decomposes into the four temperaments alternating in gender. Since the eight archetypes are ubiquitous and fundamental, with a bit of familiarization they become easy to recognize. Consequently, determining someone's supertype is fairly straightforward. Knowing the supertype is key to understanding the person and is a desirable starting point in psychoanalysis. Many people are "possessed" by a particular archetype from their spectrum. Others have issues that stem from a difficult relation with their complement, or even complete lack of communication 


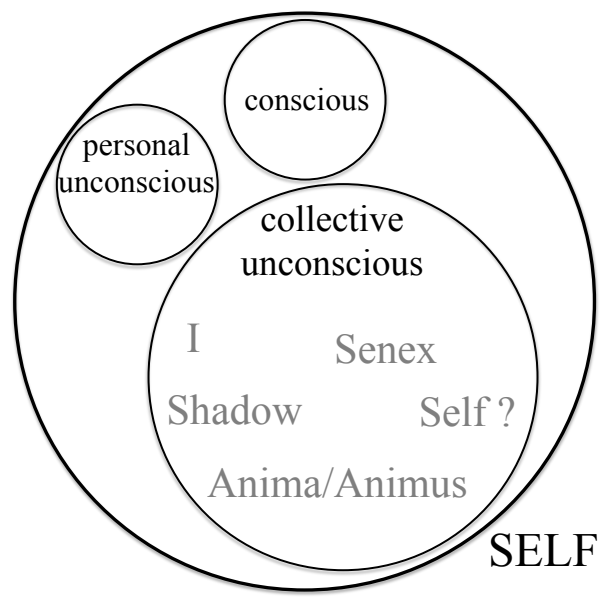

(a)

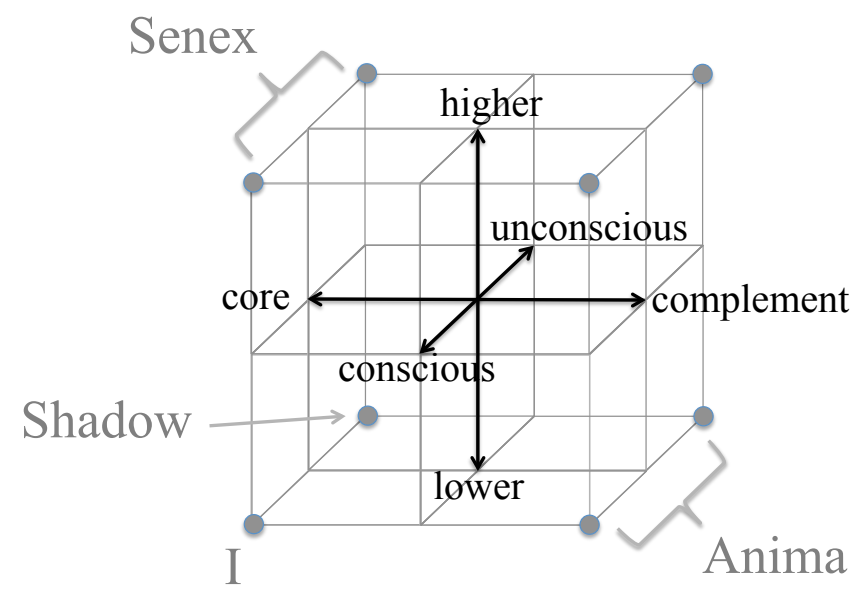

(b)

Figure 8: Jung's view of the psyche (a) vs. our model of the Self (b)

with their complement; this becomes much easier to detect if you can form a mental image of the complement and its personality. To truly "know thyself" it is helpful if not mandatory to understand the structure of thy Self.

The second contribution is that towards distilling and unifying the vast and profound opus of C.G. Jung ${ }^{9}$ into a coherent model of the Self:

- We have given the concept of the Self and the collective unconscious a serious makeover. Fig. 8a is a graphical representation of the Jungian view of the psyche. The totality-Self contains the conscious and personal unconscious as well as the collective unconscious with its different archetypes: the I, the Shadow, the Anima/Animus, the Senex. Fig. 8b represents our model of the Self. Recall that the core-complement and higher-lower dualities divide the Self into four quadrants. Since each quadrant has a conscious and unconscious part we can add a third spatial dimension for the conscious-unconscious duality and represent the Self as a cube divided into eight octants. The conscious together with the I archetype can be associated with the conscious lower core octant. The personal unconscious together with the Shadow archetype can be associated with the unconscious lower core octant. We equate both conscious and unconscious parts of the lower complement to the Anima/Animus; and both conscious and unconscious parts of the higher core to the Senex (for males). Jung presented the path of individuation as successively integrating the Shadow, Anima and Senex. Thus we start from the conscious lower complement, the most evident corner of the cube, and gradually integrate the other corners of the Self-cube until the full Self is realized.

- We have baked Jung's theory of types into the model of the Self by equipping each quadrant of the Self of with its own (undirected) psychological type. Equivalently, we can say that each octant has a directed type comprising two cognitive functions. Thus for every supertype there is a one-to-one mapping from the corners of the cube from Fig. $8 \mathrm{~b}$ to the corners of the cube from Fig. 2b. In this sense the theory of supertypes completes Jung's antipodal correspondence between the conscious and unconscious types.

- We have made contact with the Seven Sermons to the Dead, Jung's most dense and poetic work, and the inspiration for much of his subsequent contributions. We have identified

\footnotetext{
${ }^{9}$ An excellent non-technical overview can be found in [9].
} 
the symbolic "gods and demons" with our irrational and irrational elements, respectively. Another lead is that the pleroma (i.e. the Self) is characterized as a union of pairs of opposites ${ }^{10}$. Accordingly we have encountered numerous dualities in the course of the present work: solve-coagula, rational-irrational, thinking-feeling, intuition-sensation, introversionextroversion, conscious-unconscious, masculine-feminine, self-other, higher-lower, space-time, stable-dynamic, ascending-descending, spirituality-sexuality, hot-cold, dry-wet, excitationdeexcitation, fast-slow, etc.

- A few other major ideas of Jung include the theory of complexes and the notion of synchronicity. We have hinted at the likely relation of the latter to the inseparability of the inner and outer aspects of the complement. As for the former, in an upcoming paper we associate complexes with undifferentiated mixtures of two or more of the eight elements. Thus the key to dissolving complexes is to break them down into constituent elements.

Thirdly, beyond unifying existing ideas, we have introduced a qualitatively new way of describing psychological reality. In ancient times it was believed that physical reality was literally composed of the classical elements: Earth, Water, Fire and Air. Over time science has disproven this view and replaced it by elementary particles: electrons, photons, quarks. Albeit precise and experimentally verifiable, the elementary particles do not speak to the psyche at all. So something has been lost. Actually, the ancients were not as simple-minded as we may think. They were just mixing up physical and psychological reality.

We have taken on the task to cleanly differentiate the two. There is a psychological reality that can be modelled in a way akin to the physical one, yet cannot be deduced from it and does not contradict it. The eight elements introduced in this work, Spirit, Matter, Libido, Enchantment, Love, Truth, Princess and Hero, are proposed as the elementary particles of psychological reality. Just like the elementary particles of physics are characterized by charge, mass and spin, the eight elements have binary properties such as gender (masculine vs. feminine), attitude (introverted vs. extroverted), state (higher vs. lower) and plane (rational vs. irrational). From them the archetypal personalities, the eight archetypes (related to the classical elements of the ancients) are built, which in turn make up the supertype, the psychological type of the Self. Conversely, in order to demonstrate that the eight elements are indeed the fundaments of psychological reality we must start with the end product, the human personality, and experimentally validate the theory of supertypes (in the manner of Section 7 ) in a statistically meaningful way.

\section{A Appendix: Description of the eight elements}

In this section we give a somewhat freestyle account of the eight elements in an attempt to make them more relatable.

\footnotetext{
${ }^{10}$ Quoting from the "Sermons":

We must, therefore, distinguish the qualities of the pleroma. The qualities are PAIRS OF OPPOSITES, such as -

The Effective and the Ineffective.

Fullness and Emptiness.

Living and Dead.

Difference and Sameness.

D.

The pairs of opposites are qualities of the pleroma which are not, because each balances each. As we are the pleroma itself, we also have all these qualities in us. Because the very ground of our nature is distinctiveness, therefore we have these qualities in the name and sign of distinctiveness.
} 
Matter. Matter is the irrational lower feminine element. It is most widespread in our material existence, mistaken for something common or even unpleasant. It is experienced as contraction, constriction, embodiment, touch, inertia, heaviness, density. Contrasted with more dynamic elements it may be seen as impediment, friction, resistance, effort, grasping, fixation, repetition. It is related to presence, nowness, immediacy, blackness, oblivion, death with respect to the past and future. It is the basis for both pleasure and pain.

Spirit. Spirit is the irrational higher masculine element. In contrast to Matter it is most rare in our material existence, and because of this often mistaken for the ultimate human realization. It is experienced as complete expansion, panoramic awareness, infinity, eternity, blinding white light, weightlessness, effortlessness, divine inspiration, creativity, freshness, intelligence, clarity.

Libido. Libido is the irrational lower masculine element. Like Spirit, it has to do with expansion, but it is on a bodily level, like Matter. It is experienced as life force, a rush of energy, stepping on the gas pedal, vitality, potency, virility, invincibility, empowerment, inner joy and outer freedom of movement: it is fantastic to be alive. It also enables us to fight for survival.

Enchantment. Enchantment is the irrational higher feminine element. Like Matter is has to do with contraction, but on a cosmic level, like Spirit. It is the experience of being magnetized, mesmerized, fascinated, struck by lightning, love at first sight. You are surrendering to the universe: life is magical.

Love. Love is the rational lower feminine element. It is experienced deeply, it pierces the core of your being. It is the feeling a mother has for her child; it is the true love of a woman. It is pure, but decidedly of the Earth. It overcomes all imperfection, forgives every mistake; in fact it is nourished by imperfection. It is deep red, mature, ripens slowly, grows with time. It is the basis for all communication: we cannot survive without exchange, sharing, giving, being part of a community. It is the basis for a wide range of emotions: sadness, hurt feelings, self pity, jealousy.

Truth. Truth is the rational higher masculine element. It is the universal law, divine order, reaching out to fathom the universe. It is cold, unwavering, inescapable, perfect. It is the basis for logic, mathematics and rules. At its worst it is rigidity and self-righteousness. At its best it is like an empty blue sky.

Princess. The Princess is the rational higher feminine element. She is embodied, unlike Love which is vast. She is the need to attract, but in an embodied way, not in the vast manner in which Love attracts. She is beauty, vanity even; she is radiant, eternal, vibrant, heavenly, virginal.

Hero. The Hero is the rational lower masculine element. He is embodied, unlike Truth which is vast. He is outward moving, directed action, embodied purpose. He is man and his vocation, his mission. The Hero has a goal and he is going for it.

\section{B Appendix: Metaphors for the archetypes}

\section{B.1 Archetypes in relation to the life cycle}

The masculine and feminine archetypes do not show up in the context of supertypes only. The human life can be divided into four stages, each of which approximates a particular archetype. Nowadays there is not a big difference between the life of a man and the life of a woman. However 
for millenia men and women have been playing well defined gender roles which are, unsurprisingly, based on the archetypes. For men:

1. Early childhood is marked by the Heavenly Hero archetype. Your fantasy is very active, you want to achieve impossible things, you want to reach the stars and slay dragons. You also tend to be spoiled and feel very important. This is the ascending phase.

2. The Hero archetype symbolizes the struggle to carve out a place for yourself in the world. You overcome your childhood fantasies, set yourself realistic goals, work hard, and move from one challenge to the next. You think on your feet and learn to collaborate with others. This lower phase typically spans the period from puberty to midlife.

3. At some point you have achieved certain seniority. Perhaps you are a manager or proprietor. You are in a position to benefit from the work of others. This is the descending phase of the Earthly God.

4. After retirement you are ready to move into the final phase and slowly prepare for death. As there is nothing more to accomplish in this world, you become interested in spiritual matters, and Truth without direct benefit or application. This is the higher phase of the God archetype.

For women:

1. Early childhood is marked by the Princess archetype. You are daddy's little princess, you have that innocent beauty, you believe in fairy tales. This is the higher phase.

2. The Heavenly Woman archetype characterizes the period between puberty and motherhood. You are no more a little girl, but not yet a woman. You are testing your femininity, you are discovering how to attract and seduce, you are aware of your power over men. The possibilities seem limitless. You are not looking for any kind of completion. This is the ascending phase.

3. The Woman period lasts during the childbearing years. You gradually move from sensual to maternal. You are busy multitasking between the various aspects of family life, which requires great energy. This is the lower phase.

4. Your sons are married by now and your daughters-in-law have moved in and become your subordinates. You are the queen of a wider household comprising multiple generations. The Earthly Princess characterizes this final period of your life. She is a stern matriarchal, rather than motherly, figure. This is the descending phase.

Fig. 9 shows the familiar archetype cycle, represented as a clockwise sequence: higher $\rightarrow$ descending $\rightarrow$ lower $\rightarrow$ ascending etc. Interestingly, the male and female life cycles both progress in a counterclockwise fashion. The dashed arrows, starting with ascending and ending with higher, show the male life cycle. The solid arrows, starting with higher and ending with descending, show the female life cycle.

\section{B.2 Archetypes in relation to the four seasons}

With the advances of civilization we have become increasingly shielded from the whims of nature. However for millennia life has been about the interplay between two protagonists: Man and Nature. In this context Man represents the masculine principle and Nature represents the feminine principle.

Nature goes through the cycle of the four seasons and Man responds to them, adapts to them, complements them. The four seasons of Nature correspond to the four feminine archetypes, while Man appropriately manifests the complementary masculine archetypes. 


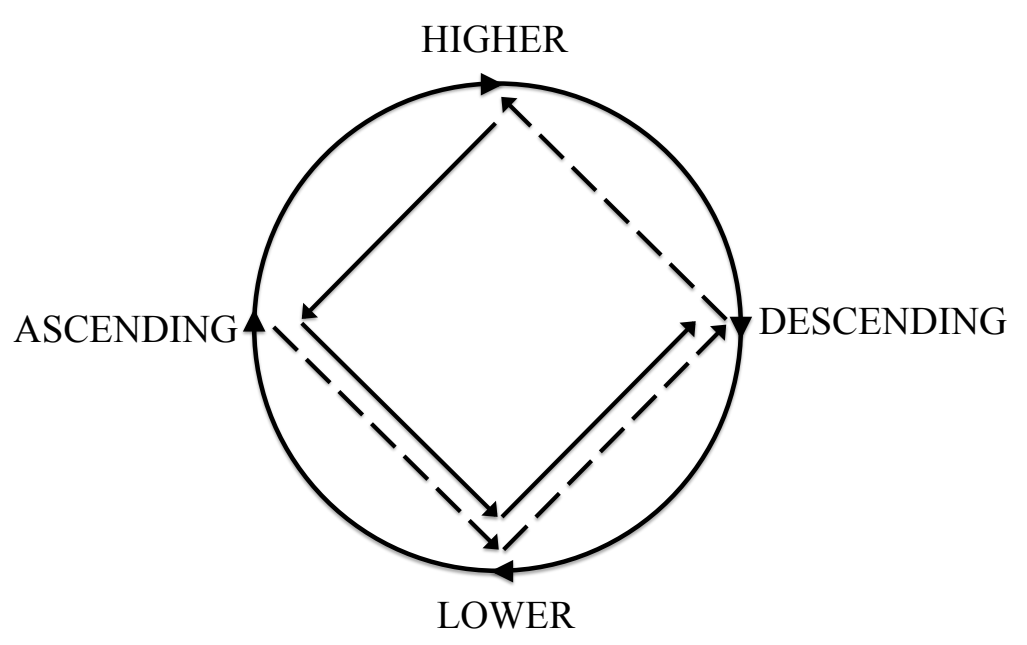

Figure 9: The archetype cycle is traversed in reverse during one's lifetime. The dashed arrows represent the male and the solid arrows represent the female case.

1. In the springtime Nature is a young Princess, beautiful, fresh and joyful. Man is a Heavenly Hero, enraptured by her. In high spirits, he needs no particular goal, roaming around and enjoying his freedom.

2. In the summertime Nature becomes a seductive Heavenly Woman, promising enjoyment and passion. Man is relaxed, taking it slow, and there is a pervasive feeling of well-being. Everything is spontaneously fulfilled: he is a God.

3. In the autumn Nature has matured and is ready to bear fruit. Man has come down from his lofty heavens and taken interest in Nature and what she has to offer. He is ready to exploit her. She is a Woman and he is an Earthly God.

4. In the wintertime Nature is a cold beauty, an Earthly Princess. The Hero needs to work hard, find ways to keep warm, to survive. He needs great persistence and skill in order to conquer her.

\section{Archetypes across cultures}

The difference in cultures around the globe can be to a large extent attributed to the preponderance of one particular archetype. The Hero archetype dominates the U.S.A. and generally the AngloSaxon world. The God archetype dominates Russia and Iran. The Heavenly Hero dominates Germany and Japan. The Earthly God dominates Turkey and much of the Muslim world. Much of east Asian culture is in the sign of the Princess. Africa is in the sign of the Woman. The Heavenly Woman dominates Italy and Latin America. The Earthly Princess is preponderant in Sweden and nordic culture in general, and also characterizes the Native American spirit.

Usually a secondary archetype can be identified, for instance the one complementary to the dominant one. Thus England is Hero but also the Earthly Princess, which gives it a flavour different from the U.S.A. Japan and China are both Princess and Heavenly Hero. Jewish culture is at its core related to the God archetype, but the Earthly God is responsible for its commercial success, 
while its strife for excellence comes from the Heavenly Hero. Italy is Heavenly Woman but also Hero. France is a choleric mixture of Heavenly Hero and Heavenly Woman. Spain is Heavenly Hero and Woman. Serbia is in the sign of the Woman, but on the masculine side there is an internal conflict between the Heavenly Hero and Earthly God.

\section{References}

[1] Jung, C.G. (1971). "Psychological Types", Collected Works of C.G. Jung, Volume 6, Princeton, N.J.: Princeton University Press. (Original work published 1921)

[2] Myers, I. B. (1962). The Myers-Briggs Type Indicator: Manual (1962). Consulting Psychologists Press.

[3] Digman J.M. (1990). "Personality structure: Emergence of the five-factor model", Annual Review of Psychology. 41: 417-440.

[4] Devetak, I. (2020). "Quantum Teleportation and Jungian Psychology", preprint, https://arxiv.org/abs/2008.01079

[5] Jung, C.G. (1969). "Archetypes and the Collective Unconscious", Collected Works of C.G. Jung, Volume 9 (Part 1), Princeton, N.J.: Princeton University Press.

[6] Jung, C.G. (1969). "Aion: Researches into the Phenomenology of the Self", Collected Works of C.G. Jung, Volume 9 (Part 2), Princeton, N.J.: Princeton University Press. (Original work published 1951)

[7] C. G. Jung, The Red Book: Liber Novus, ed. Sonu Shamdasani, Norton, 2009

[8] Jung, C.G. (1968). "Structure and Dynamics of the Psyche", Collected Works of C.G. Jung, Volume 8, Princeton, N.J.: Princeton University Press.

[9] Stein, M. (1998). "Jung's Map of the Soul: an Introduction", Open Court, Chicago 